\title{
Affective ratings of sound stimuli
}

\author{
Jaime Redondo, Isabel Fraga, Isabel Padrón, and Ana Piñeiro \\ University of Santiago, Santiago de Compostela, Spain
}

\begin{abstract}
This article present the Spanish assessments of the 111 sounds included in the International Affective Digitized Sounds (IADS; Bradley \& Lang, 1999b). The sounds were evaluated by 159 participants in the dimensions of valence, arousal, and dominance, using a computer version of the Self-Assessment Manikin (Bradley \& Lang, 1994). Results are compared with those obtained in the American version of the IADS, as well as in the Spanish adaptations of the International Affective Picture System (P. J. Lang, Bradley, \& Cuthbert, 1999; Moltó et al., 1999) and the Affective Norms for English Words (Bradley \& Lang, 1999a; Redondo, Fraga, Padrón, \& Comesaña, 2007).
\end{abstract}

As has been recently stated (Spreckelmeyer, Kutas, Urbach, Altenmüller, \& Münte, 2006), evaluation of emotional scenes most frequently requires integration of information from auditory and visual channels. More specifically, Spreckelmeyer et al. found different patterns of cross-modal influences, which varied depending on the emotional valence of the stimuli. In an affect rating task, responses to voice stimuli were more likely to be modulated by the affective valence of a picture concomitantly presented than vice versa. In another recent article, Baumgartner, Lutz, Schmidt, and Jäncke (2006) suggested that the presentation of emotional pictures evokes a more "cognitive mode" of emotion perception, whereas when those pictures are accompanied by congruent musical stimuli, they seem to evoke strong "emotional feelings."

These theoretical considerations highlight the need for normalized and well-adapted databases of stimuli from the different modalities. Thus, in line with our previous work - the Spanish adaptation of the Affective Norms for English Words (ANEW; Bradley \& Lang, 1999a; Redondo, Fraga, Padrón, \& Comesaña, 2007) - we now present the evaluations of emotional sounds from the International Affective Digitized Sounds (IADS; Bradley \& Lang, 1999b) in Spanish participants. Since 1999, the Center for Research in Psychophysiology has been developing these databases of emotional stimuli, as well as the IAPS (International Affective Picture System; P. J. Lang, Bradley, \& Cuthbert, 1999), also adapted for use with Spanish people by Moltó et al. (1999). Therefore, our primary goal is to expand the IADS for use in a Spanish sample population. This will make it possible to investigate cross-cultural differences between North Americans' and Spaniards' sounds affective ratings.

With regard to our first aim, the necessity and usefulness of normalized stimuli databases are obvious, since they allow the direct comparison of different categories of stimuli and sensorial modalities, as well as different ex- perimental results. Over the past few years, the processing of emotional pictures and its physiological correlates have been broadly investigated (e.g., Bradley \& Lang, 2000b). In many of these works, either the IAPS or its adaptations have been employed (e.g., Buodo, Sarlo, \& Palomba, 2002; Cándido et al., 2006; Schimmack, 2005). However, less research has been done with the aim of measuring cognitive, behavioral, and physiological reactions to affective words and sounds - that is, research using the ANEW and the IADS. In fact, some researchers have studied the effects of different kinds of emotional sound stimuli, such as music (Khalfa, Peretz, Blondin, \& Manon, 2002) or nonlinguistic human affective sounds (e.g., Fecteau, Armony, Joanette, \& Belin, 2005), but all of these investigations have used different materials; and although some of them employed sets of sounds previously evaluated by the participants (e.g., Pollak, Holt, \& Wismer-Fries, 2004), results are too heterogeneous to be compared.

If we consider auditory stimuli in isolation, there is no doubt that there are quite a lot of pleasant versus unpleasant/ arousing versus nonarousing sounds in everyday contexts (e.g., laughing, car wreck/scream, yawn, etc.). Therefore, although humans are thought to be a profoundly visual species, it is also true that sometimes a rapid response to an emotional sound may be necessary in terms of welfare and survival. Fortunately, a line of systematic research has been initiated in the past decade, including some experiments that employed the IADS (e.g., Anttonen, 2005; Bradley \& Lang, 2000a; Seifritz et al., 2003). In sum, it is the availability of the IAPS, ANEW, and IADS - three emotional stimulus databases built on the twin bases of identical theoretical perspective and methodological procedure - that makes it possible to compare experiments and results. With the study presented here, at last three normalized instruments will be available for investigating reactions to emotional stimuli in any of their modalities (pictures, words, and sounds) in Spanish people. 
The collection of the emotional sound ratings in Spanish people will allow us to make a direct comparison between these data and those from Bradley and Lang's (1999b) American sample. Thus, it will be of great interest to test whether international differences previously found in IAPS and ANEW assessments hold for the IADS as well (Redondo, Fraga, \& Padrón, 2006; Redondo et al., 2007).

The theoretical background that supports this work is the dimensional perspective of emotions (e.g., Bradley, 1994; A. Lang, Dhillon, \& Dong, 1995; P. J. Lang, 1995), which originates in Wundt (1896) and Osgood (Osgood, Suci, \& Tannenbaum, 1957) and which conceptualizes emotion as having three basic underlying dimensions along which the entire range of human emotions can be arranged. The two primary dimensions are valence (which ranges from pleasant to unpleasant) and arousal (which ranges from calm to excited); the third dimension is dominance or control (ranging from in control to out of control). The present study assessed all three dimensions of emotion using a single measure: the Self-Assessment Manikin (SAM; Bradley \& Lang, 1994).

\section{METHOD}

\section{Participants}

A total of 159 students of psychology (135 women and 24 men) at the University of Santiago, ranging from 19-32 years old $(M=$ $22.85, S D=1.78$ ), enrolled voluntarily and contributed to the final data. The ratings of the sounds were obtained throughout November and December, 2006.

\section{Materials}

The sounds employed in this study were the same as those employed by Bradley and Lang (1999b) in their normative study. ${ }^{1}$ In order to automate the assessment process, experimental sessions were programmed with the SuperLab Pro (Abboud \& Sugar, 1997) software. This software controlled the presentation of instructions and practice sounds at the computer display, as well as the presentation of sounds via headphones, and it also registered the ratings that participants entered using the keyboard.

The 111 sounds obtained from the IADS were divided into three blocks of 37 sounds each. Thus, during the experimental session, each participant rated one of these three blocks of sounds (altogether, 53 participants rated one of the three blocks), because the assessment of all 111 sounds would have been too exhausting.

The duration of each sound was the same as that in the original normative study (Bradley \& Lang, 1999b) - that is, $6 \mathrm{sec}$ - and its intensity was measured using a PCE-322A sound level meter and the values of reference provided by Bradley and Lang (2000a). The last column of the Appendix shows the maximum peak of intensity registered during each 6 -sec presentation.

\section{Procedure}

During the rating session, each participant was seated in a soundproof experimental booth facing a computer monitor screen. Participants could initially read the instructions on the screen and rate three practice sounds. ${ }^{2}$ After reading the instructions and before evaluating the experimental sounds, any questions were resolved. In order to avoid order effects, the presentation of sounds was randomized for each participant. Ratings were made using a computer version of the SAM. Thus, participants could rate each sound on a 9-point scale for each affective dimension (valence, arousal, and dominance; for more details on the use of the SAM, see, e.g., Bradley \& Lang, 2000a; Redondo et al., 2007). Each rating session lasted approximately $25 \mathrm{~min}$.
The ratings of the sounds in each of the three affective dimensions are included in the Appendix.

\section{RESULTS AND DISCUSSION}

\section{Spaniards' IADS Ratings}

The sound rating distribution in the affective space defined by the dimensions of valence and arousal can be seen in Figure 1. This distribution shows the boomerang shape also found by Moltó et al. (1999) and Redondo et al. (2007) in the corresponding Spanish adaptations of the IAPS and ANEW. In fact, although the linear correlation between valence and arousal $(r=.453, p<.001)$ accounted for $20.5 \%$ of the variance, the quadratic correlation between the two dimensions $(r=.687, p<.001)$ accounted for $47.2 \%$ of the variance. This quadratic correlation was higher than that found in the Spanish adaptations of the IAPS $(r=.64)$ and ANEW $(r=.522)$.

\section{Spain-U.S.A. Comparisons}

Global comparisons. The distribution of the ratings in the affective space is virtually identical to that found in the original normative study of the IADS (Bradley \& Lang, 1999b, Figure 3, p. 17). In fact, a very high Pearson correlation was obtained between the affective ratings of Spanish and North American people: $r=.918$ for valence, $r=.903$ for arousal, and $r=.914$ for dominance $(p<$ .001 in all cases). These Spain-U.S.A. correlations are even higher (in all three dimensions) than those obtained in our recent adaptation of the ANEW $(r=.916, r=.746$, and $r=.720$ for valence, arousal, and dominance, respectively; see Redondo et al., 2007).

Therefore, as was the case with words, globally Americans and Spaniards rated the sounds of the IADS in a similar way. This also happens when picture ratings made by American participants are compared with those made by Spanish and other European people (see Bradley, Codispoti, Sabatinelli, \& Lang, 2001; Moltó et al., 1999).

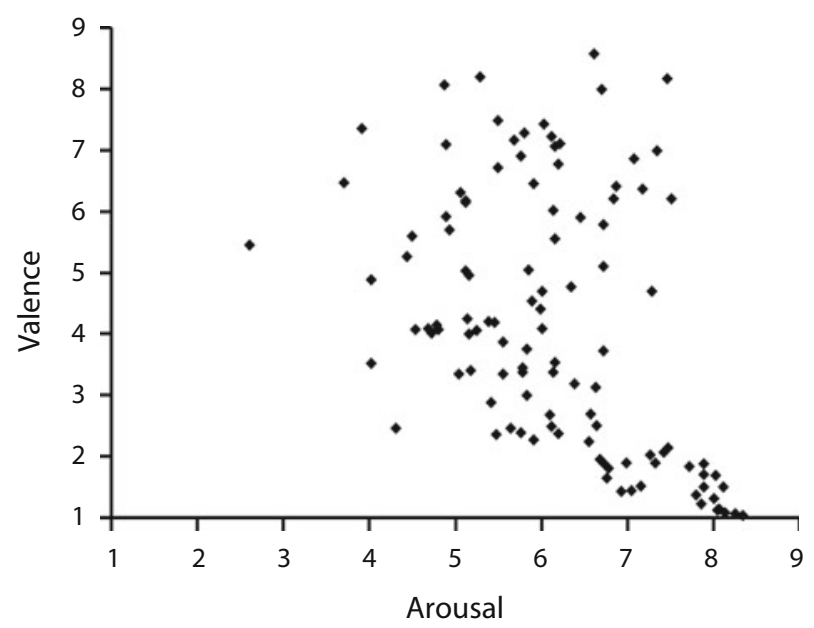

Figure 1. Distribution of the mean values corresponding to the ratings of the 111 sounds in the dimensions of valence and arousal. 
Dimensional analyses. Despite the above general similarities, in the Spanish adaptations of the IAPS and ANEW, some differences between the Spanish and the North American assessments were found when the three affective dimensions were compared with each other. That is why we carried out a comparative analysis between the values obtained in the present study and those found by Bradley and Lang (1999b) with American people. Means of both the Spanish and American ratings for each affective dimension are shown in Table $1 .^{3}$

The comparisons of the means revealed significant differences in the valence $[t(220)=2.998, p=.003]$ and arousal $[t(220)=-2.406, p=.017]$ dimensions. However, no significant differences were found in the dominance dimension $[t(220)=1.353, p=.177]$.

Thus, as can be seen in Table 1, Americans tended to rate IADS sounds with a more positive mean valence than did the Spaniards. The same result had been found by Redondo et al. (2007) using ANEW words as stimuli, but not by Moltó et al. (1999) using IAPS images; these authors failed to find significant differences between those two populations in the valence dimension. Also, when responding in this dimension, Spaniards used a wider range of values than that used by Americans in the SAM scale, the difference being slightly higher than 1 .

In the arousal dimension, Americans used a wider range of values in the SAM scale, rating the IADS sounds as being less activating than did Spanish participants. This result was also obtained with ANEW words and IAPS images (see Redondo et al., 2007, and Moltó et al., 1999, respectively).

Finally, the absence of statistically significant differences between the American and Spanish populations for the dominance dimension differs from results found in the Spanish normative studies of the ANEW and IAPS. Thus, both Redondo et al. (2007), using words, and Moltó et al. (1999), using images, found that American participants obtained significantly higher values in the dominance dimension than did the Spanish participants. As can be seen in Table 1, the ranges used by both populations differed very little (the difference being .13).

In order to explore differences found between Americans and Spaniards in valence and arousal ratings, sound assessments in both dimensions were dichotomized. In valence ratings, the above-mentioned global tendency for all 111 sounds was maintained when Spain-U.S.A. ratings for both the 55 most unpleasant sounds [low valence: mean Spain $=2.33$, mean U.S.A. $=3.47 ; t(108)=$ $-5.59, p=.008$ ] and the 56 most pleasant sounds [high valence: mean Spain $=5.96$, mean U.S.A. $=6.44$; $t(110)=-2.22, p=.012]$ were compared. Nevertheless, when Spain-U.S.A. ratings for the 55 most nonarousing sounds were compared, no significant differences were found $[$ mean Spain $=5.21$, mean U.S.A. $=4.69 ; t(108)=$ $3.47, p=.207]$, but those differences again followed the global tendency when ratings for the 56 most arousing sounds [high arousal: mean Spain $=7.08$, mean U.S.A. $=$ $6.79 ; t(110)=-2.07, p=.045]$ were compared.

In conclusion, American people rate IADS sounds as being higher in the valence dimension than do Spanish
Table 1

Means, Standard Deviations, and Range Values of the Spanish and American Population Ratings in the Three Affective Dimensions

\begin{tabular}{lccccccc}
\hline & \multicolumn{3}{c}{ Spain } & & \multicolumn{3}{c}{ U.S.A. } \\
\cline { 2 - 4 } \cline { 7 - 8 } Dimension & $M$ & Range & $S D$ & & $S D$ & $M$ & Range \\
\hline Valence & 4.17 & 1.69 & 7.55 & & 4.97 & 1.70 & 6.54 \\
Arousal & 6.15 & 1.75 & 5.74 & & 5.75 & 1.94 & 6.06 \\
Dominance & 4.51 & 1.92 & 5.23 & & 4.76 & 1.94 & 5.10 \\
\hline
\end{tabular}

people, independent of the pleasantness or unpleasantness of those sounds. However, although globally Americans rate IADS sounds as being lower than do Spaniards in the arousal dimension, this difference comes across in the arousing rather than in the nonarousing sounds. ${ }^{4} \mathrm{Cul}-$ tural factors may be responsible for these differences. For instance, the "bomb" sound is rated by Spanish people as being much more unpleasant and arousing, perhaps due to the fact that that sound evokes terrorist events from the recent past, during which bombs were frequently used in Spain. On the other hand, "football" is rated as being much more pleasant by the Americans, perhaps because it is clearly identified with American football, which is rarely played in Spain. Therefore, in future research, it would be interesting to analyze the role of cultural differences in valence and arousal assessments, while also controlling for the possible interaction of gender. As Bradley et al. (2001) have suggested,

Cross-cultural studies, especially those investigating men and women raised in nontraditional Western societies, as well as additional developmental research would assist in determining the impact of biologicalgenetic or sociocultural variables in affecting men's and women's reactions to affective cues. (p. 317)

In sum, with regard to comparisons between the present data and those obtained previously with the IAPS and ANEW, for the valence dimension, it seems that the type of stimuli (sounds and words vs. images) determines the differences between the ratings of Spanish and American participants. For instance, for the arousal dimension, Spanish participants always show a higher emotional reactivity, independent of the kind of stimuli employed. Finally, although the Spanish participants possess a lower perception of control relative to words or images, this difference disappears in Americans when sounds are employed as stimuli.

Therefore, although we must keep in mind that American and Spanish sample populations evaluated IADS sounds in a highly similar way, it is also true that some slight differences have been found that should not be overlooked. In fact, the same happened with the IAPS and ANEW. We now know that Spanish people show a stronger emotional reactivity (arousal) across stimuli; they tend to assess words and sounds, but not images, as being slightly more unpleasant (valence) than do Americans; and, finally, the Americans show a higher feeling of control (dominance) over emotional images and words, but not over sounds. From an anthropological perspective, one 
wonders whether those differences might be explained in terms of specific contextual factors or broad cross-cultural characterizations (Vrana \& Rollock, 2002). These reflections put our data in touch with the old issue of whether emotions are universal - or, more pointedly, to what extent, and at what level of analysis, cultural variation exists (Elfenbein, Mandal, Ambady, Harizuka, \& Kumar, 2002). Until researchers have a clear answer to these questions, they will have to be cautious in drawing conclusions on the basis of cross-cultural research on emotion (Diener, Oishi, \& Lucas, 2003). In this sense, it seems advisable to base conclusions on data obtained from a variety of procedures and measures, using a set of normalized stimuli databases.

In this sense, as has been commented in previous work (Redondo et al., 2007), the IADS, IAPS, and ANEW constitute powerful instruments for investigation. It is worth noting that the identification of the stimuli through a number or label in each of these databases enhances the replication of results and makes scientific communication easier. Thus, one could easily select some stimuli from their ratings in each affective dimension. Moreover, comparative studies between sensorial modalities could be carried out by selecting images, words, and sounds with similar values in valence and arousal, in order to determine the extent to which different emotional stimuli give rise to different cognitive, physiological, and behavioral reactions in a variety of populations. As Bradley and Lang (2000a) have suggested elsewhere, as long as we can find consistent overlapping among all these measures, "the thesis that these responses reflect activation of a common emotional system is supported" (p. 204).

With the present work, we complete a line of research initiated some years ago by Moltó et al. (1999) and Redondo et al. (2007). These normative studies paved the way for future systematic research on affective reactions to emotional stimuli. Such research will now be possible, in an exhaustive and controlled way, among Spanish populations.

\section{AUTHOR NOTE}

The authors thank Margaret Bradley, who provided us with the IADS, and Amavia Méndez for her help in data collection, as well as for her work with the computer processing of sound ratings. We also thank an anonymous reviewer for his or her helpful comments. Correspondence concerning this article should be addressed to J. Redondo, Faculdad de Psicología, Universidade de Santiago, 15706 Santiago de Compostela, Spain (e-mail: jredondo@usc.es).

\section{REFERENCES}

Abboud, H., \& Sugar, D. (1997). SuperLab Pro 1.04 [Computer software]. San Pedro, CA: Cedrus Corporation.

ANTTONEN, J. (2005). Using the EMFI chair to measure the user's emotion-related heart rate responses. Unpublished doctoral dissertation, University of Tampere, Tampere, Finland.

Baumgartner, T., Lutz, K., SChmidt, C. F., \& JÄNCKe, L. (2006). The emotional power of music: How music enhances the feeling of affective pictures. Brain Research, 1075, 151-164.

Bradley, M. M. (1994). Emotional memory: A dimensional analysis. In S. H. M. Van Goozen, N. E. Van de Poll, \& J. A. Sergeant (Eds.), Emotions: Essays on emotion theory (pp. 97-134). Hillsdale, NJ: Erlbaum.

Bradley, M. M., Codispoti, M., Sabatinelli, D., \& Lang, P. J.
(2001). Emotion and motivation II: Sex differences in picture processing. Emotion, 1, 300-319.

Bradley, M. M., \& Lang, P. J. (1994). Measuring emotion: The selfassessment manikin and the semantic differential. Journal of Behavioral Therapy \& Experimental Psychiatry, 25, 49-59.

Bradley, M. M., \& Lang, P. J. (1999a). Affective norms for English words (ANEW): Stimuli, instruction manual and affective ratings (Tech. Rep. No. C-1). Gainesville, FL: Center for Research in Psychophysiology, University of Florida.

Bradley, M. M., \& LANG, P. J. (1999b). International affective digitized sounds (IADS): Stimuli, instruction manual and affective ratings (Tech. Rep. No. B-2). Gainesville, FL: Center for Research in Psychophysiology, University of Florida.

BRADLEY, M. M., \& LANG, P. J. (2000a). Affective reactions to acoustic stimuli. Psychophysiology, 37, 204-215.

Bradley, M. M., \& Lang, P. J. (2000b). Measuring emotion: Behavior, feeling, and physiology. In R. D. Lane \& L. Nadel (Eds.), Cognitive neuroscience of emotion (pp. 242-276). New York: Oxford University Press.

Buodo, G., Sarlo, M., \& Palomba, D. (2002). Attentional resources measured by reaction times highlight differences within pleasant and unpleasant, high arousing stimuli. Motivation \& Emotion, 26, 123-138.

Cándido, A., Perales, J. C., Catena, A., Maldonado, A., Guadarrama, L., Beltrán, R., et al. (2006). Efectos de la inducción emocional en el aprendizaje causal [Emotion and causal learning]. Psicológica, 27, 243-267.

Diener, E., Oishi, S., \& Lucas, R. E. (2003). Personality, culture, and subjective well-being: Emotional and cognitive evaluations of life. Annual Review of Psychology, 54, 403-425.

Elfenbein, H. A., Mandal, M. K., Ambady, N. A., Harizuka, S., \& Kumar, S. (2002). Cross-cultural patterns in emotion recognition: Highlighting design and analytical techniques. Emotion, 2, 75-84.

Fecteau, S., Armony, J. L., Joanette, Y., \& Belin, P. (2005). Judgment of emotional nonlinguistic vocalizations: Age-related differences. Applied Neuropsychology, 12, 40-48.

Khalfa, S., Peretz, I., Blondin, J.-P., \& Manon, R. (2002). Eventrelated skin conductance responses to musical emotions in humans. Neuroscience Letters, 328, 145-149.

Lang, A., Dhillon, K., \& Dong, Q. (1995). The effects of emotional arousal and valence on television viewers' cognitive capacity and memory. Journal of Broadcasting \& Electronic Media, 39, 313-327.

LANG, P. J. (1995). The emotion probe: Studies of motivation and attention. American Psychologist, 50, 372-385.

Lang, P. J., Bradley, M. M., \& Cuthbert, B. N. (1999). International affective picture system (IAPS): Affective ratings of pictures and instruction manual. Gainesville, FL: Center for Research in Psychophysiology, University of Florida.

Moltó, J., Montañés, S., Poy, R., Segarra, P., Pastor, M. C., Tormo, M. P., ET AL. (1999). Un nuevo método para el estudio experimental de las emociones: El international affective picture system (IAPS). Adaptación española [A new method for the experimental study of emotions: The IAPS. Spanish adaption]. Revista de Psicologia General y Aplicada, 52, 55-87.

Osgood, C., Suci, G. J., \& Tannenbaum, P. H. (1957). The measurement of meaning. Champaign, IL: University of Illinois.

Pollak, S. D., Holt, L. L., \& Wismer-Fries, A. B. (2004). Hemispheric asymmetries in children's perception of nonlinguistic human affective sounds. Developmental Science, 7, 10-18.

Redondo, J., Fraga, I., \& Padrón, I. (2006, July). Diferencias culturales y de género en la evaluación de palabras emocionales [Cultural and gender differences in evaluating emotion words]. Poster presented at the 6th Congress of the Spanish Society of Experimental Psychology. Santiago de Compostela, Spain.

Redondo, J., Fraga, I., Padrón, I., \& Comesaña, M. (2007). The Spanish adaptation of ANEW (Affective Norms for English Words). Behavior Research Methods, 39, 600-605.

Schimmack, U. (2005). Attentional interference effects of emotional pictures: Threat, negativity, or arousal? Emotion, 5, 55-66.

Seifritz, E., Esposito, F., Neuhoff, J. G., LÜthi, A., Mustovic, H. Dammann, G., ET AL. (2003). Differential sex-independent amygdala response to infant crying and laughing in parents versus nonparents. Biological Psychiatry, 54, 1367-1375. 
Spreckelmeyer, K. N., Kutas, M., Urbach, T. P., Altenmüller, E., $\&$ MÜNTE, T. F. (2006). Combined perception of emotion in pictures and musical sounds. Brain Research, 1070, 160-170.

VRANA, S. R., \& Rollock, D. (2002). The role of ethnicity, gender, emotional content, and contextual differences in physiological, expressive, and self-reported emotional responses to imagery. Cognition \& Emotion, 16, 165-192.

WUNDT, W. (1896). Compendio de psicología [Outlines of psychology]. Madrid: La España Moderna.

\section{NOTES}

1. The CD-ROM with both the sounds of the IADS and the normative ratings of the United States population can be obtained on request from the CSEA (cseamedia@phhp.ufl.edu).

2. These sounds (which obviously do not correspond to any of the experimental sounds of the IADS) were obtained from the Banco de Sonidos (Sound Bank) of the Spanish Ministry of Education and Science (recursos.cnice.mec.es/bancoimagenes/sonidos/index/php). A pleasant sound (children laughing), an unpleasant sound (woman screaming), and a neutral one (water running) were selected. The duration of these sounds was adjusted to the 6-sec experimental presentations of the sounds of the IADS.

3. Although Bradley \& Lang's (1999b) study does not provide for the values shown in Table 1, they have been calculated from the data that the authors have so kindly provided us.

4. In order to identify the sounds with the greater size differences, we calculated the absolute difference between Spanish and American ratings in valence and arousal dimensions. Thus, in low-valence sounds, the highest difference was obtained with "football" (\#362) and "bomb" (\#699) sounds (2.9 and 2.6, respectively). In high-valence sounds, the maximum difference occurred with "rollercoaster" (\#360) and "baseball" (\#353) sounds (2.2 and 1.8, respectively). Finally, in high-arousal sounds, the biggest difference was again obtained with "bomb" (\#699) and "fight" (\#290) sounds (2.3 and 1.6, respectively). In all of these cases, the direction of the differences followed the global tendency (i.e., the Americans rated sounds with higher values in valence and lower values in arousal than did the Spaniards).

\section{APPENDIX}

Below, the description is the original label that describes the content of each sound taken from the IADS. The sound number is a number that identifies each of the 111 sounds and corresponds to the original number in the IADS. The means $(M \mathrm{~s})$ and standard deviations $(S D$ s) for valence, arousal, and dominance are included. Intensity, measured in $\mathrm{db}(\mathrm{A})$, of each sound is included. This value corresponds to the maximum peak of intensity registered along the 6 -sec presentation of each sound.

Table A1

Means, Standard Deviations, and Decibels of Each Sound in the International Affective Digitized Sounds (IADS), in the Three Affective Dimensions

\begin{tabular}{|c|c|c|c|c|c|c|c|c|}
\hline \multirow[b]{2}{*}{ Description } & \multirow[b]{2}{*}{ Sound No. } & \multicolumn{2}{|c|}{ Valence } & \multicolumn{2}{|c|}{ Arousal } & \multicolumn{2}{|c|}{ Dominance } & \multirow[b]{2}{*}{$\mathrm{dB}$} \\
\hline & & $M$ & $S D$ & $M$ & $S D$ & $M$ & $S D$ & \\
\hline TomCat & 100 & 4.21 & 2.24 & 5.38 & 1.75 & 5.53 & 2.17 & 70.0 \\
\hline PuppyCry & 105 & 3.55 & 2.44 & 6.15 & 1.86 & 4.45 & 2.01 & 68.6 \\
\hline DogGrowl & 106 & 1.89 & 1.49 & 7.89 & 1.35 & 2.38 & 2.00 & 74.9 \\
\hline Carousel & 109 & 6.02 & 2.31 & 6.13 & 1.54 & 5.38 & 1.78 & 71.5 \\
\hline BabyLaugh & 110 & 8.58 & 0.93 & 6.60 & 1.78 & 6.55 & 1.89 & 71.8 \\
\hline MusicBox & 111 & 7.43 & 2.07 & 6.02 & 2.15 & 5.91 & 2.09 & 75.2 \\
\hline KidsInPark & 112 & 6.45 & 2.15 & 5.91 & 1.48 & 5.62 & 1.87 & 71.5 \\
\hline Cows & 113 & 4.96 & 2.08 & 5.15 & 1.91 & 4.83 & 2.06 & 72.4 \\
\hline Bees & 115 & 1.66 & 1.27 & 6.75 & 2.09 & 2.55 & 1.76 & 67.8 \\
\hline Wasp & 116 & 1.53 & 0.91 & 7.15 & 1.63 & 3.62 & 2.18 & 74.2 \\
\hline Rooster & 120 & 5.11 & 2.34 & 6.72 & 1.78 & 5.04 & 1.99 & 78.4 \\
\hline Pig & 130 & 2.28 & 1.57 & 5.91 & 1.78 & 3.58 & 2.29 & 78.0 \\
\hline Chickens & 132 & 5.04 & 2.12 & 5.11 & 1.84 & 5.26 & 2.13 & 78.2 \\
\hline Bear & 133 & 3.19 & 1.91 & 6.38 & 1.36 & 3.47 & 1.89 & 65.2 \\
\hline Cardinal & 151 & 6.15 & 2.26 & 5.11 & 1.90 & 5.51 & 1.85 & 75.1 \\
\hline Tropical & 152 & 6.19 & 2.29 & 5.11 & 2.12 & 5.85 & 1.97 & 77.5 \\
\hline CountryNight & 171 & 5.26 & 2.26 & 4.43 & 1.97 & 4.98 & 2.04 & 68.1 \\
\hline EroticCouple & 200 & 6.87 & 2.15 & 7.08 & 1.91 & 5.91 & 1.99 & 70.1 \\
\hline EroticFem 1 & 201 & 6.38 & 2.51 & 7.17 & 1.76 & 5.75 & 2.31 & 69.6 \\
\hline EroticFem2 & 202 & 6.42 & 2.50 & 6.87 & 2.04 & 5.66 & 1.91 & 75.6 \\
\hline EroticFem3 & 205 & 6.32 & 2.22 & 5.06 & 2.48 & 5.42 & 1.97 & 68.9 \\
\hline Shower & 206 & 7.36 & 1.57 & 3.91 & 1.93 & 6.92 & 1.88 & 69.0 \\
\hline EroticMale1 & 210 & 6.21 & 2.39 & 6.83 & 2.02 & 5.98 & 2.16 & 70.6 \\
\hline EroticCouple2 & 215 & 6.21 & 2.36 & 7.51 & 1.48 & 5.21 & 2.11 & 74.5 \\
\hline EroticCouple3 & 216 & 7.00 & 1.93 & 7.34 & 1.83 & 5.89 & 1.95 & 68.8 \\
\hline BoyLaugh & 220 & 7.11 & 1.98 & 6.21 & 1.77 & 5.85 & 1.78 & 68.9 \\
\hline MaleLaugh & 221 & 6.72 & 2.06 & 5.49 & 1.94 & 5.72 & 1.81 & 67.1 \\
\hline ClapGame & 225 & 5.60 & 1.63 & 4.49 & 1.69 & 5.58 & 1.78 & 71.4 \\
\hline Laughing & 226 & 6.77 & 2.23 & 6.19 & 1.71 & 5.77 & 1.81 & 71.7 \\
\hline Giggling & 230 & 6.91 & 1.63 & 5.75 & 1.47 & 5.79 & 1.83 & 69.7 \\
\hline NoseBlow & 251 & 2.47 & 1.50 & 4.30 & 2.05 & 4.66 & 2.10 & 71.7 \\
\hline MaleSnore & 252 & 2.47 & 1.94 & 5.64 & 2.41 & 3.51 & 2.03 & 67.9 \\
\hline VideoGame & 254 & 3.87 & 2.01 & 5.55 & 1.91 & 5.85 & 1.77 & 67.2 \\
\hline BabyCry & 261 & 2.04 & 1.14 & 7.26 & 1.47 & 3.74 & 2.17 & 78.1 \\
\hline Yawn & 262 & 5.45 & 1.87 & 2.60 & 1.60 & 4.96 & 2.08 & 68.2 \\
\hline Whistlin & 270 & 5.70 & 2.00 & 4.92 & 1.75 & 5.83 & 1.95 & 68.0 \\
\hline FemScream2 & 276 & 1.51 & 1.61 & 8.11 & 0.99 & 2.17 & 1.68 & 72.6 \\
\hline
\end{tabular}


APPENDIX (Continued)

Table A1 (Continued)

\begin{tabular}{|c|c|c|c|c|c|c|c|c|}
\hline \multirow[b]{2}{*}{ Description } & \multirow[b]{2}{*}{ Sound No. } & \multicolumn{2}{|c|}{ Valence } & \multicolumn{2}{|c|}{ Arousal } & \multicolumn{2}{|c|}{ Dominance } & \multirow[b]{2}{*}{$\mathrm{dB}$} \\
\hline & & $M$ & $S D$ & $M$ & $S D$ & $M$ & $S D$ & \\
\hline FemScream 3 & 277 & 1.32 & 0.94 & 8.00 & 1.58 & 2.25 & 1.88 & 70.7 \\
\hline ChildAbuse & 278 & 1.13 & 0.62 & 8.04 & 1.27 & 3.36 & 2.38 & 79.9 \\
\hline Attack1 & 279 & 1.04 & 0.19 & 8.34 & 0.83 & 1.81 & 1.37 & 77.9 \\
\hline Funeral & 280 & 3.00 & 2.07 & 5.83 & 1.77 & 3.91 & 2.17 & 75.3 \\
\hline Attack2 & 285 & 1.08 & 0.33 & 8.25 & 0.92 & 2.43 & 2.07 & 70.3 \\
\hline Victim & 286 & 1.15 & 0.84 & 8.06 & 1.31 & 1.70 & 1.20 & 70.9 \\
\hline CardiacArrest & 287 & 1.91 & 1.40 & 6.72 & 1.95 & 2.68 & 1.83 & 70.4 \\
\hline Fight & 290 & 1.23 & 0.70 & 7.85 & 1.29 & 2.25 & 1.37 & 76.9 \\
\hline Prowler & 291 & 1.81 & 1.04 & 6.77 & 2.01 & 2.58 & 1.81 & 75.5 \\
\hline MaleScream & 292 & 1.43 & 1.17 & 6.92 & 1.80 & 2.51 & 1.64 & 70.6 \\
\hline Crowd1 & 310 & 3.13 & 1.93 & 6.62 & 1.39 & 3.64 & 1.77 & 70.8 \\
\hline Crowd2 & 311 & 4.00 & 1.79 & 5.15 & 2.04 & 4.83 & 2.25 & 69.3 \\
\hline Office 2 & 319 & 2.70 & 1.41 & 6.57 & 1.62 & 4.55 & 1.72 & 71.4 \\
\hline Office1 & 320 & 3.38 & 1.51 & 5.77 & 1.58 & 5.25 & 1.67 & 72.5 \\
\hline TypeWriter & 322 & 4.02 & 1.77 & 4.72 & 1.82 & 5.32 & 1.78 & 70.5 \\
\hline Traffic & 325 & 3.45 & 1.65 & 5.77 & 1.88 & 4.30 & 1.84 & 68.8 \\
\hline Applause & 351 & 7.23 & 1.40 & 6.11 & 1.87 & 6.28 & 1.75 & 65.1 \\
\hline SportsCrowd & 352 & 5.79 & 1.94 & 6.72 & 1.26 & 5.28 & 1.43 & 72.1 \\
\hline Baseball & 353 & 5.91 & 1.88 & 6.45 & 1.58 & 5.28 & 1.79 & 73.2 \\
\hline Writing & 358 & 3.36 & 1.51 & 5.04 & 1.85 & 5.26 & 2.04 & 70.9 \\
\hline RollerCoaster & 360 & 4.70 & 2.64 & 7.28 & 1.88 & 3.83 & 2.07 & 76.7 \\
\hline Restaurant & 361 & 4.55 & 2.18 & 5.89 & 1.63 & 5.45 & 1.74 & 71.6 \\
\hline Football & 362 & 2.89 & 1.49 & 5.42 & 1.84 & 4.06 & 1.70 & 72.7 \\
\hline CourtSport & 370 & 5.92 & 1.77 & 4.89 & 2.00 & 5.87 & 2.30 & 62.7 \\
\hline JackHammer & 380 & 1.45 & 0.87 & 7.04 & 1.57 & 3.11 & 2.02 & 73.4 \\
\hline Jet & 400 & 4.09 & 2.01 & 6.00 & 2.11 & 3.74 & 2.01 & 71.3 \\
\hline Applause & 401 & 7.08 & 1.60 & 6.15 & 1.68 & 6.02 & 1.79 & 74.4 \\
\hline Helicopter1 & 403 & 3.38 & 1.93 & 6.13 & 1.63 & 4.25 & 2.03 & 73.4 \\
\hline Helicopter2 & 410 & 3.75 & 1.77 & 5.83 & 2.07 & 3.72 & 1.63 & 74.3 \\
\hline Countdown & 415 & 4.70 & 1.76 & 6.00 & 1.63 & 4.51 & 2.12 & 69.0 \\
\hline CarHorns & 420 & 2.25 & 1.34 & 6.55 & 1.77 & 4.06 & 2.09 & 74.2 \\
\hline TireSkids & 422 & 2.08 & 1.72 & 7.42 & 1.43 & 3.19 & 2.07 & 75.0 \\
\hline Injury & 423 & 2.49 & 1.61 & 6.11 & 1.68 & 3.66 & 1.59 & 75.2 \\
\hline CarWreck & 424 & 1.09 & 0.35 & 8.13 & 1.33 & 2.04 & 1.75 & 79.3 \\
\hline Train & 425 & 5.06 & 2.17 & 5.85 & 1.80 & 4.60 & 1.95 & 69.9 \\
\hline Wind & 500 & 3.36 & 2.25 & 5.55 & 1.82 & 4.02 & 2.33 & 73.1 \\
\hline PlaneCrash & 501 & 1.96 & 1.37 & 6.68 & 2.20 & 2.40 & 1.59 & 66.0 \\
\hline EngineFailure & 502 & 2.40 & 1.49 & 5.75 & 2.16 & 2.77 & 1.55 & 67.5 \\
\hline BikeWreck & 600 & 1.15 & 0.60 & 8.06 & 1.38 & 2.09 & 1.67 & 80.6 \\
\hline ColonialMusic & 601 & 5.57 & 2.24 & 6.15 & 1.68 & 5.51 & 2.04 & 76.2 \\
\hline Thunderstorm & 602 & 4.19 & 2.39 & 5.45 & 1.81 & 3.64 & 1.99 & 70.0 \\
\hline CboyIndians & 610 & 4.77 & 2.06 & 6.34 & 1.98 & 4.83 & 2.08 & 69.7 \\
\hline MayDay & 625 & 2.51 & 1.61 & 6.64 & 1.33 & 3.28 & 2.11 & 72.4 \\
\hline Bombs & 626 & 2.15 & 1.67 & 7.47 & 1.44 & 2.79 & 2.14 & 76.8 \\
\hline HowlingRain & 627 & 1.38 & 0.95 & 7.79 & 1.21 & 2.28 & 1.87 & 79.9 \\
\hline Raging Fire & 698 & 1.51 & 0.87 & 7.89 & 1.53 & 2.30 & 1.69 & 79.4 \\
\hline Bomb & 699 & 1.91 & 1.38 & 7.32 & 1.58 & 2.98 & 2.01 & 74.1 \\
\hline ToiletFlush & 700 & 3.53 & 1.92 & 4.02 & 1.82 & 5.38 & 2.28 & 72.8 \\
\hline Fan & 701 & 4.08 & 2.06 & 4.79 & 2.03 & 4.68 & 1.74 & 68.5 \\
\hline Belch & 702 & 2.36 & 1.95 & 5.47 & 1.88 & 3.83 & 2.00 & 73.1 \\
\hline TouchTone & 704 & 4.15 & 1.74 & 4.77 & 2.04 & 5.85 & 2.34 & 67.1 \\
\hline RotaryDial & 705 & 4.42 & 1.45 & 5.98 & 1.98 & 4.85 & 2.19 & 71.4 \\
\hline War & 706 & 1.91 & 1.62 & 6.98 & 1.62 & 2.85 & 2.00 & 71.3 \\
\hline ClockTick & 708 & 3.42 & 1.56 & 5.17 & 2.07 & 4.36 & 2.20 & 69.9 \\
\hline AlarmClock & 709 & 1.72 & 1.28 & 7.89 & 1.55 & 3.81 & 2.18 & 80.8 \\
\hline Cuckoo & 710 & 3.74 & 2.24 & 6.72 & 1.69 & 4.49 & 2.23 & 74.9 \\
\hline Sirens & 711 & 1.85 & 1.71 & 7.72 & 1.23 & 2.30 & 1.58 & 77.8 \\
\hline Buzzer & 712 & 1.70 & 1.29 & 8.02 & 1.13 & 2.45 & 1.50 & 80.9 \\
\hline BrushTeeth & 720 & 4.09 & 1.84 & 4.68 & 1.96 & 6.13 & 2.09 & 71.6 \\
\hline Beer & 721 & 7.09 & 1.47 & 4.89 & 1.82 & 6.72 & 1.84 & 72.9 \\
\hline Walking & 722 & 2.68 & 1.40 & 6.09 & 1.68 & 4.47 & 2.19 & 69.7 \\
\hline Radio & 723 & 4.06 & 2.22 & 5.25 & 1.83 & 5.47 & 2.34 & 75.8 \\
\hline Chewing & 724 & 4.25 & 2.37 & 5.13 & 1.94 & 5.34 & 2.17 & 68.1 \\
\hline SodaFizz & 725 & 4.08 & 2.02 & 4.53 & 1.89 & 5.00 & 1.93 & 72.3 \\
\hline Cork & 726 & 4.89 & 1.75 & 4.02 & 1.73 & 5.28 & 1.92 & 63.0 \\
\hline GlassBreak & 730 & 2.38 & 1.24 & 6.19 & 1.75 & 4.25 & 1.84 & 77.5 \\
\hline Natives & 802 & 7.28 & 1.77 & 5.79 & 2.08 & 6.21 & 1.63 & 69.2 \\
\hline
\end{tabular}


APPENDIX (Continued)

Table A1 (Continued)

\begin{tabular}{|c|c|c|c|c|c|c|c|c|}
\hline \multirow[b]{2}{*}{ Description } & \multirow[b]{2}{*}{ Sound No. } & \multicolumn{2}{|c|}{ Valence } & \multicolumn{2}{|c|}{ Arousal } & \multicolumn{2}{|c|}{ Dominance } & \multirow[b]{2}{*}{$\mathrm{dB}$} \\
\hline & & $M$ & $S D$ & $M$ & $S D$ & $M$ & $S D$ & \\
\hline Beethoven & 810 & 8.21 & 1.08 & 5.28 & 2.54 & 6.81 & 1.75 & 71.0 \\
\hline Bach & 811 & 7.49 & 1.60 & 5.49 & 2.01 & 5.83 & 1.95 & 69.8 \\
\hline Choir & 812 & 6.47 & 2.25 & 3.70 & 2.14 & 5.43 & 2.10 & 68.8 \\
\hline RockNRoll & 815 & 8.17 & 0.99 & 7.45 & 1.70 & 6.75 & 1.56 & 74.0 \\
\hline Guitar & 816 & 8.08 & 1.11 & 4.87 & 2.31 & 6.66 & 1.40 & 67.5 \\
\hline FunkMusic & 820 & 8.00 & 1.39 & 6.70 & 2.00 & 6.60 & 1.76 & 75.0 \\
\hline BagPipes & 826 & 7.17 & 1.76 & 5.68 & 2.08 & 5.60 & 1.90 & 76.1 \\
\hline
\end{tabular}

(Manuscript received February 8, 2007;

revision accepted for publication February 8,2008 .) 